\title{
STUDI PENENTUAN LOKASI UNTUK PENGEMBANGAN BUDIDAYA RUMPUT LAUT DI WILAYAH PERAIRAN TELUK SALEH, SUMBAWA, NTB
}

\author{
STUDY OF LOCATION DETERMINATION FOR SEAWEED CULTURE DEVELOPMENT IN \\ SALEH BAY, SUMBAWA, NTB
}

\author{
Komang Iwan Suniada ${ }^{1}$ dan B. Realino S. $^{2}$ \\ ${ }^{1}$ Balai Penelitian dan Observasi Laut \\ Br. Dangin Berawah, Ds. Perancak, Jembrana Bali 82251 \\ Telp (0365) 44266, Fax (0365) 44270 \\ ${ }^{2}$ Pusat Pengkajian dan Perekayasaan Teknologi Kelautan dan Perikanan \\ E-mail : komang_prtk@yahoo.com
}

Diterima tanggal: 11 Maret 2014, diterima setelah perbaikan: 18 Juli 2014, disetujui tanggal: 24 Juli 2014

\begin{abstract}
ABSTRAK
Studi ini dilaksanakan sebagai salah satu bentuk dukungan terhadap kebijakan strategis Kementerian Kelautan dan Perikanan yang mendorong peningkatan produksi perikanan melalui kegiatan budidaya perikanan. Teluk Saleh yang terletak di Pulau Sumbawa NTB merupakan salah satu lokasi yang potensial untuk pengembangan budidaya laut. Tujuan dari studi ini adalah memberikan informasi kepada pemerintah setempat mengenai daerah yang sesuai untuk pengembangan budidaya rumput laut di perairan Teluk Saleh. Studi ini menggunakan data yang bersumber dari data satelit penginderaan jauh (Terra/Aqua MODIS dan Landsat), data survey lapangan serta data sekunder. Data satelit penginderaan jauh digunakan untuk menghasilkan informasi suhu permukaan laut, konsentrasi klorofil-a serta untuk pemetaan dasar perairan; data survey lapangan yang diukur adalah nitrat, fosfat, salinitas, $\mathrm{pH}$, DO, Total Dissolves Solid (TDS), kecepatan arus dan kecerahan perairan; sedangkan data sekunder yang digunakan adalah data bathymetri. Datadata tersebut kemudian diberi bobot dan skor yang disesuaikan dengan komoditi rumput laut yang akan dibudidayakan. Perangkat lunak Sistem Informasi Geografi dengan menggunakan metode tumpang susun (overlay) digunakan untuk menganalisis parameter-parameter tersebut di atas, dimana semakin tinggi skornya menunjukkan daerah tersebut semakin sesuai untuk pengembangan budidaya rumput laut. Studi ini menghasilkan informasi bahwa area yang potensial bagi pengembangan budidaya rumput laut di perairan Teluk Saleh adalah sekitar 25.532 Ha.
\end{abstract}

Kata kunci: budidaya rumput laut, penginderaan jauh, Sistem Informasi Geografi, Teluk Saleh

\begin{abstract}
This study was carried out to support the strategic plan of the Ministry of Marine Affairs and Fisheries of Republic of Indonesia that seeks to increase fisheries production through the aquaculture, especially by developing seaweed culture around Sumbawa regency. The aim of this study is to provide information about potential area for seaweed culture around Teluk Saleh water territory, Sumbawa Regency, West Nusa Tenggara.Remote sensing data (Terra/Aqua MODIS and Landsat satellite image), field survey data and secondary data were used for this study. Remote sensing data were used to produce sea surface temperature (SST), chlorophyll-a information and bottom substrate mapping; field survey data provided nitrate, phosphate, salinity, pH, DO, TDS, flow velocity, water transparency while secondary data was used to provide bathymetry information. Geographical Information System software was used to analyze this study by using overlay technique for all parameter, which had previously been weighted and scored based on the criteria of aquatic habitat suitability for seaweed culture. Higher score indicates that the area more suitable for seaweed culture activities.The results showed that the potential area suitable for seaweed culture around Teluk Saleh water territory, Sumbawa Regency, West Nusa Tenggara is about $25.532 \mathrm{Ha}$.
\end{abstract}

Keywords: seaweed culture, remote sensing, Geographic Information System, Saleh Bay 


\section{PENDAHULUAN}

Kabupaten Sumbawa merupakan kabupaten yang mengembangkan rumput laut sebagai salah produk unggulan di bidang perikanan dan kelautan. Sejak tahun 2010 hingga 2012, kawasan budidaya rumput laut di wilayah Kabupaten Sumbawa berkembang pesat, sehingga Pemerintah Pusat memberikan predikat sebagai kabupaten berkinerja terbaik dan menjadikannya kabupaten percontohan komodi ekspor rumput laut.

Sementara ini, Dinas Kelautan dan Perikanan Kabupaten Sumbawa telah menetapkan 6 kawasan pengembangan budi daya rumput laut, meliputi kawasan timur, yakni Labuhan Aji-Tarano, Labuhan Sangoro-Maronge, Labuhan Kuris-Lape, Labuhan Terata-Lape dan Tanjung Bele-Moyo Hilir. Kemudian di kawasan tengah ada di Pulau Medang-Labuhan Badas dan di kawasan Barat tepatnya di Labuhan Mapin-Alas Barat.

Teluk Saleh, yang secara administratif berada di tiga kabupaten yakni Kabupaten Sumbawa, Dompu dan Bima, merupakan perairan yang menjadi prioritas pengembangan budidaya rumput laut dengan harapan selain adanya sumber usaha baru yang akan berpengaruh bagi pendapatan masayarakat pesisir,juga sedikit demi sedikit mengurangi ketergantungan masyarakat terhadap kegiatan penangkapan ikan yang cenderung menurun.

Proses penentuan lokasi budidaya yang tepat merupakan salah satu faktor yang penting untuk menunjang keberhasilan suatu kegiatan budidaya rumput laut. Parameter-parameter perairan penting yang harus diperhatikan antara lain, kriteria topografi lokasi (keterlindungan dari angin dan ombak besar), parameter fisik perairan (suhu, kecepatan arus, kekeruhan perairan, kecerahan perairan) parameter kimia (konsentrasi nitrat, fosfat, oksigen terlarut, $\mathrm{pH}$, salinitas) dan parameter biologi yaitu organisme yang merugikan maupun fitoplankton berbahaya (Ambas, 2006; Sulma, Mannopo, \& Indarto, 2008; FPIK Unri, 2008). Informasi mengenai daerah potensial bagi pengembangan budidaya rumput laut disusun dengan menggunakan aplikasi Sistem Informasi Geografis yang telah dipergunakan secara luas di dunia, diantaranya untuk budidaya kerangkerangan di Baynes Sound, Canada (Carswell, Cheesman \& Anderson, 2006), site selecton untuk mangrove oyster raft di Pulau Margarita, Venezuela (Buitrago, Rada, Hernandez \& Buitrago, 2005), pemodelan parameter lingkungan untuk budidaya laut di Sinola State, Mexico (Aguilar-Manjarez and Ross, 1995), site selection di Canary Island, Tenerife (Perez, Ross, Telfer, \& del Campo Barquin, 2003), lokasi yang sesuai untuk Japanese scallop di Teluk Funka, Hokkaido (Radiarta Saitoh, \& Miyazono, 2008), pemilihan lokasi budidaya di Teluk Tomini (Utojo, Mansyur, Tangko, Hasnawi \& Mulia, 2007), site selection untuk budidaya di Teluk Kupang (Hartoko \& Kangkan, 2009), budidaya ikan kerapu di Perairan Morotai (Suniada, 2011) serta budidaya rumput laut di wilayah perairan Sumba Timur (Suniada, Realino \& Indriyawan, 2012).

Tujuan dari penelitian ini adalah untuk memberikan informasi mengenai daerah potensial bagi pengembangan budidaya rumput laut pada wilayah penelitian, sehingga dapat dijadikan sebagai masukan bagi pemerintah daerah setempat untuk pengembangan kawasan budidaya di wilayah perairan Teluk Saleh.

\section{BAHAN DAN METODE}

\subsection{Waktu dan Tempat}

Penelitian dilakukan di wilayah perairan Teluk Saleh antara Kecamatan Lape-Lopok, Plampang dan Kecamatan Empang, Kabupaten Sumbawa, NTB $\left(8^{\circ} 25^{\prime}-8^{\circ} 45^{\prime}\right.$ LS dan $117^{\circ} 35^{\prime}-118^{\circ} 10^{\prime}$ BT $)$ karena daerah tersebut merupakan salah satu lokasi potensial bagi pengembangan rumput laut di Kabupaten Sumbawa. Pengambilan data lapangan dilakukan pada 27 stasiun pengamatan, dan dilaksanakan pada tanggal 31 Mei - 7 Juni 2012 antara jam 09.00 WITA sampai dengan jam 16.00 WITA.Sebaran pengambilan data bersifat acak dan dianggap mewakili daerah dekat pantai, daerah yang jauh dari pantai serta daerah-daerah disekitar Pulau Rakit, Pulau Ngali dan Pulau Liang yang merupakan pulau-pulau besar yang ada di dalam Teluk. Beberapa parameter seperti suhu, salinitas, $\mathrm{pH}$, oksigen terlarut (Dissolved Oxygen; DO), kecepatan arus, kecerahan perairan, Muatan Padatan Tersuspensi (MPT) diukur langsung di lokasi pengamatan, sedangkan parameter nitrat dan fosfat dianalisis di Laboratorium Riset Kelautan BPOL, Perancak, Bali. 


\subsection{Alat dan Bahan Survey Lapangan}

Alat dan bahan yang digunakan pada saat survey pengambilan data lapangan diantaranya adalah: wahana survey yang berupa kapal nelayan, GPS, salinometer, $\mathrm{pH}$ meter, water quality checker, water sampler, current meter, seichi disk, botol sampel $1000 \mathrm{ml}$, serta coolbox untuk menyimpan sampel air.

\subsection{Data yang Digunakan}

Data yang digunakan pada penelitian ini adalah data satelit, data insitu dan data sekunder.Data satelit digunakan untuk mengetahui konsentrasi suhu permukaan laut, konsentrasi klorofil-a permukaan laut serta prediksi sebaran substrat dasar. Sebaran suhu dan konsentrasi klorofil-a permukaan laut diidentifikasi menggunakan data Satelit Aqua/Terra MODIS level 2 dengan resolusi spasial $1 \mathrm{~km}$, sedangkan untuk prediksi sebaran substrat dasar menggunakan data Landsat 5 dengan resolusi $16 \mathrm{~m}$ yang diakuisisi pada tanggal 7 Maret
2012. Data Terra/Aqua MODIS yang digunakan adalah data pada periode Juni 2011 - Juli 2012 dengan jumlah data sebanyak 59 data yang bebas awan pada lokasi penelitian.

Data insitu yang diambil adalah parameterparameter perairan yang berhubungan dengan kegiatan budidaya rumput laut, diantaranya adalah nitrat, fosfat, suhu permukaan, salinitas, $\mathrm{pH}, \mathrm{DO}$, kecepatan arus, kecerahan perairan dan juga parameter kekeruhan perairan yaitu kandungan muatan padatan tersuspensi (MPT). Data suhu, salinitas, pH, DO, kecepatan arus, kecerahan perairan dan MPT dapat diukur dan diketahui langsung dengan menggunakan alat ukur portable, sedangkan parameter nitrat dan fosfat dapat diketahui setelah dilakukan analisis di laboratorium. Pengamatan dan pengambilan data sampel air dilakukan di sekitar perairan Teluk Saleh, Kabupaten Sumbawa pada 27 titik stasiun pengamatan (Gambar 1).

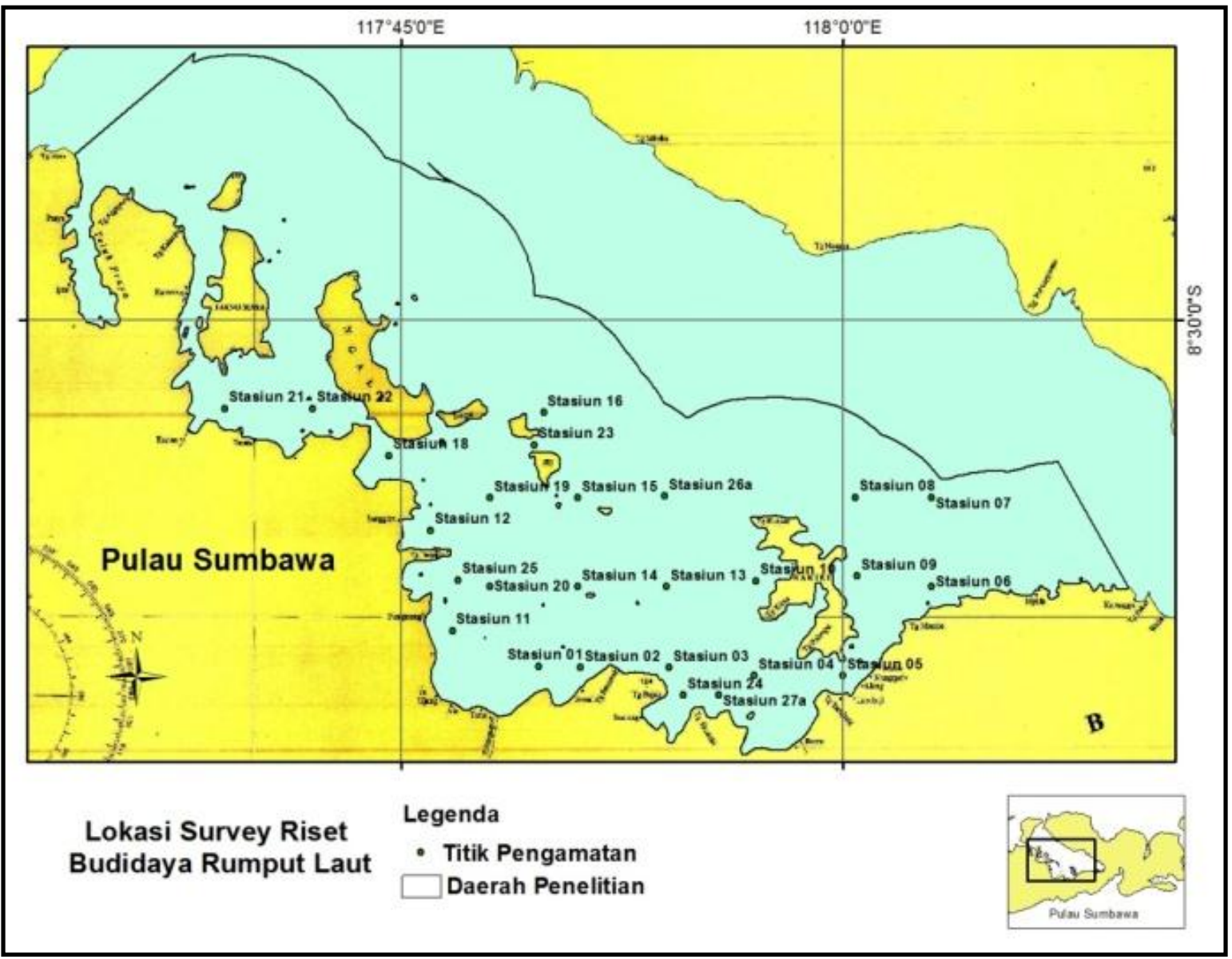

Gambar 1. Lokasi survey, titik pengukuran dan pengambilan sampel

Figure 1. Location of survey, measurement and sampling

Sumber: Peta Dishidros TNI AL 
Data sekunder yang digunakan pada penelitian ini adalah:

- Data bathymetri atau kedalaman perairan di sekitar wilayah penelitian dengan skala 1:200.000 yang dikeluarkan oleh DISHIDROS TNI AL. Data tersebut belum berupa data digital, sehingga perlu di-scan terlebih dahulu, kemudian digitasi sehingga akhirnya berbentuk data bathymetri digital untuk mempermudah proses klasifikasi selanjutnya pada software image processing.

- Data mengenai keadaan umum Kabupaten Sumbawa yang diperoleh dari website Propinsi Nusa Tenggara Barat.

\subsection{Penentuan Lokasi untuk Budidaya Rumput Laut}

Penentuan lokasi pengembangan budidaya rumput laut di wilayah perairan Teluk Saleh diperoleh dengan memanfaatkan data kualitas perairan serta data satelit penginderaan jauh. Informasi suhu permukaan laut, klorofil-a permukaan bersumber pada data citra satelit Aqua/Terra MODIS serta informasi prediksi sebaran substrat dasar diperoleh dengan menggunakan data citra satelit Landsat. Selain itu, data kedalaman perairan (bathymetri) juga diperlukan pada studi ini. Perez et al. (2003) menyatakan bahwa secara umum, suhu dan muatan tersuspensi merupakan faktor yang penting untuk menentukan lokasi yang sesuai untuk kegiatan budidaya, sedangkan menurut Hartoko dan Kangkan (2009) parameter utama yang perlu diperhatikan untuk budidaya rumput laut adalah faktor kesuburan perairan yaitu parameter nitrat dan fosfat. Dengan kajian ini, diharapkan dapat dijadikan acuan bagi pemerintah daerah setempat dalam menetapkan kawasan yang sesuai bagi lokasi perikanan budidaya, khususnya budidaya rumput laut. Diagram alir site selection di wilayah perairan Teluk Saleh, Kabupaten Sumbawa dapat dilihat pada Gambar 2.

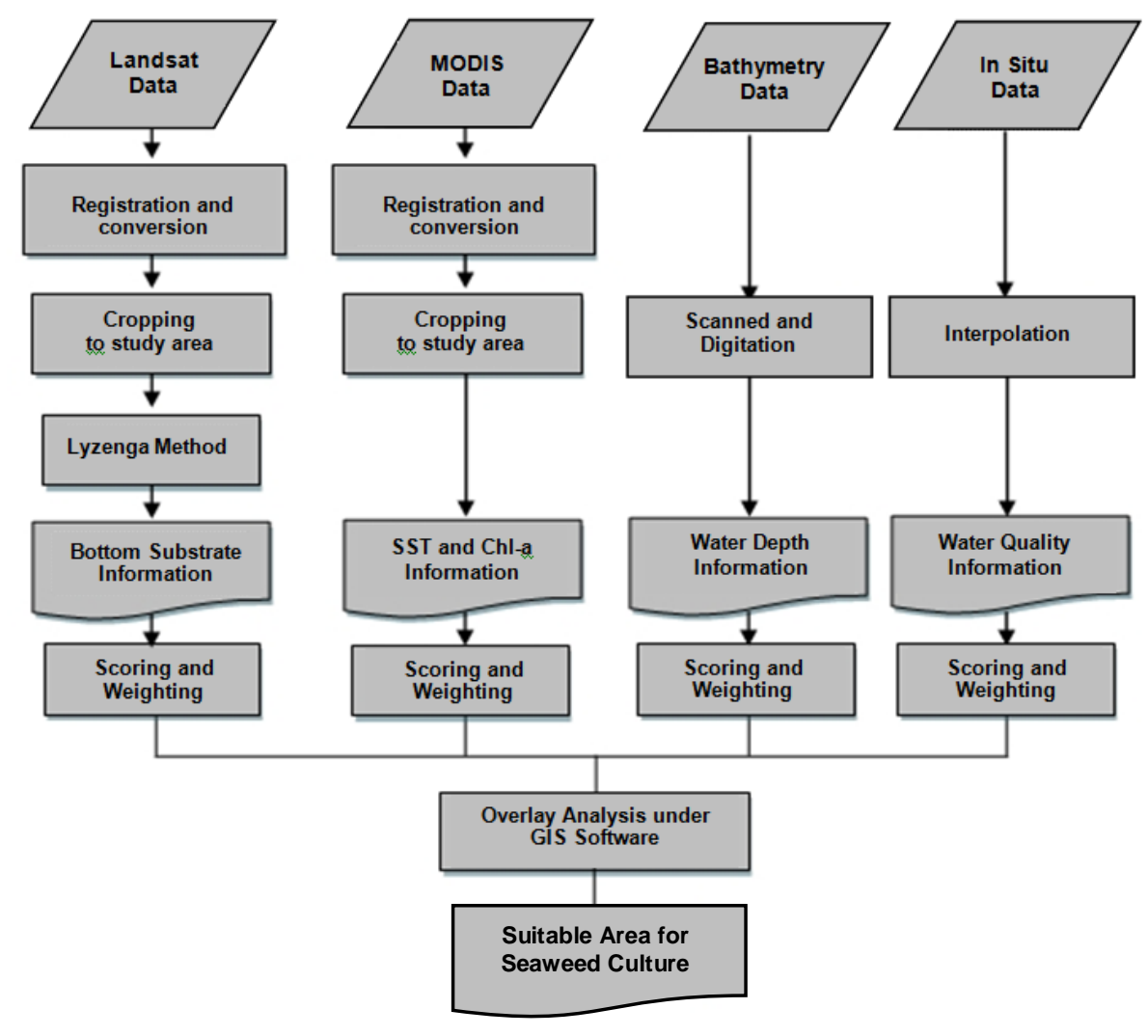

Gambar 2. Diagram alir penentuan lokasi untuk budidaya rumput laut

Figure 1. Flowchart of determination for seaweed culture

Sumber: Hartoko dan Kangkan, 2009 
Kesuburan suatu perairan merupakan faktor yang paling penting bagi kegiatan budidaya rumput laut (Hartoko dan Kangkan, 2009), sehingga bobot yang tinggi diberikan kepada parameter nutrien yaitu konsentrasi nitrat dan fosfat. Bobot tertinggi berikutnya adalah tingkat kecerahan perairan yang berkaitan erat dengan penetrasi cahaya matahari ke kolom air. Penetrasi cahaya ke kolom air sangat erat kaitannya dengan proses fotosintesis rumput laut yang menggunakan energi matahari sebagai sumber energi.

Tingkat kecerahan perairan dipengaruhi oleh banyaknya partikel-partikel pada kolom air. Partikel yang dikenal dengan istilah muatan padatan tersuspensi (MPT) tersebut bila semakin tinggi konsentrasinya pada suatu perairan akan menyebabkan perairan tersebut menjadi semakin keruh. Proses erosi yang terbawa oleh aliran sungai ataupun yang langsung masuk ke badan air merupakan salah satu penyebab utama tingginya padatan tersuspensi di perairan. Selain itu adanya proses pengadukan dasar perairan akibat pasang surut juga memberikan pengaruh yang signifikan terhadap tingginya kekeruhan perairan. Sastrawijaya (2000) dalam Sulma et al. (2008) menambahkan bahwa padatan tersuspensi dalam air umumnya terdiri dari fitoplankton, zooplankton, kotoran manusia, kotoran hewan, lumpur, sisa tanaman dan hewan serta limbah industri. Bahan-bahan yang tersuspensi di perairan alami tidak bersifat toksik, akan tetapi jika jumlahnya berlebihan dapat meningkatkan nilai kekeruhan yang selanjutnya menghambat penetrasi cahaya matahari ke kolom air (Effendi, 2000 dalam Sulma et al., 2008). Batas kandungan TSM yang diperbolehkan berdasarkan baku mutu air laut untuk biota laut adalah lebih kecil dari $80 \mathrm{mg} / \mathrm{L}$. Sedangkan kondisi perairan dikatakan ideal jika memiliki nilai di bawah $20 \mathrm{mg} / \mathrm{L}$ (Akbar dan Sudaryanto, 2002 dalam Sulma et al., 2008).

Bottom substrate berkaitan erat dengan metode budidaya yang akan dilakukan. Secara umum, bottom substrate dibedakan menjadi 3 kategori, yaitu karang, pasir dan berlumpur. Jika bottom substrate cenderung terdiri dari karang ataupun pecahan-pecahan karang, biasanya kondisi perairan akan menjadi lebih jernih daripada perairan yang berpasir atau berlumpur, sehingga teknik budidaya rumput laut yang biasa digunakan adalah dengan metode tenggelam. Berbeda halnya jika kondisi perairan adalah berpasir atau berlumpur, maka teknik budidaya yang digunakan adalah metode terapung karena pasir atau lumpur akan dapat menyebabkan keruhnya perairan dan mengganggu sistem respirasi dan fotosintesis rumput laut yang dibudidayakan.

Untuk menentukan lokasi yang sesusai bagi kegiatan budidaya rumput laut dengan menggunakan analisis spasial dan SIG, maka kriteria yang digunakan harus mengacu pada kriteria kondisi lingkungan yang sesuai bagi komoditas yang akan dibudidayakan. Kriteria tersebut akan digunakan sebagai dasar penilaian dan pembobotan dalam analisis spasial untuk memperoleh hasil yang paling sesuai dengan komoditas tersebut (Tabel 1).

\section{HASIL DAN PEMBAHASAN}

\subsection{Informasi Kualitas Perairan di Teluk Saleh, Sumbawa, NTB}

Analisis laboratorium terhadap sampel air untuk parameter fosfat menunjukkan bahwa rata-rata konsentrasi fosfat sebesar $0,001 \mathrm{mg} / \mathrm{m}^{3}$, dengan konsentrasi minimal terdeteksi $0,001 \mathrm{mg} / \mathrm{m}^{3}$ hingga maksimal $0,0019 \mathrm{mg} / \mathrm{m}^{3}$ dengan sebaran yang cenderung seragam, sedangkan untuk parameter nitrat menunjukkan bahwa rata-rata konsentrasi nitrat sebesar $0,019 \mathrm{mg} / \mathrm{m}^{3}$, dengan konsentrasi minimal terdeteksi $0,004 \mathrm{mg} / \mathrm{m}^{3}$ dan maksimal $0,065 \mathrm{mg} / \mathrm{m}^{3}$ dengan pola sebaran yang cenderung seragam pula. Senyawa nitrat dan fosfat secara alamiah berasal dari perairan itu sendiri melalui proses pelapukan ataupun dekomposisi tumbuhtumbuhan, sisa-sisa organisme mati dan buangan limbah baik limbah domestik, industri, pertanian dan peternakan yang diuraikan oleh bakteri menjadi zat hara (Wattayakorn, 1988 dalam Ulqodry, Yulisman, Syahdan \& Santoso, 2010). Kondisi nitrat pada penelitian ini lebih rendah dari yang dihasilkan oleh Radiarta et al. (2004) namun masih berkisar pada nilai baku mutu air laut yang dikeluarkan oleh Kementerian Lingkingan Hidup, sedangkan nilai fosfat yang cenderung seragam menunjukkan bahwa variasi fosfat pada laut tropis biasanya kecil, bahkan tidak ada variasi sama sekali karena tidak adanya variasi suhu yang mencolok sehingga aktifitas plankton yang memanfaatkan fosfat juga cenderung seragam (Sidjabat, 1976 dalam Ulqodry et al., 2010). 
Tabel 1. Kriteria kesesuaian kualitas perairan untuk budidaya rumput laut Table 1. Water quality suitable criteria for seaweed culture

\begin{tabular}{|c|c|c|c|c|c|c|c|c|c|c|}
\hline \multirow{2}{*}{ Parameter } & \multirow{2}{*}{ Bobot } & \multicolumn{3}{|c|}{ Tinggi } & \multicolumn{3}{|c|}{ Sedang } & \multicolumn{3}{|c|}{ Rendah } \\
\hline & & Kriteria & Skala & Skor & Kriteria & Skala & Skor & Kriteria & Skala & Skor \\
\hline $\begin{array}{l}\text { Nitrat } \\
(\mathrm{mg} / \mathrm{l})\end{array}$ & 3 & $0.9-3.2$ & 5 & 15 & $\begin{array}{l}0.7-0.8 \\
3.3-3.4\end{array}$ & 3 & 9 & $\begin{array}{l}<0.7 \\
>3.4\end{array}$ & 1 & 3 \\
\hline $\begin{array}{l}\text { Fosfat } \\
(\mathrm{mg} / \mathrm{l})\end{array}$ & 3 & $0.2-0.5$ & 5 & 15 & $\begin{array}{c}0.1-0.2 \\
0.5-1\end{array}$ & 3 & 9 & $\begin{array}{c}<0.1 \\
>1\end{array}$ & 1 & 3 \\
\hline Kedalaman (m) & 3 & $1-10$ & 5 & 15 & $11-15$ & 3 & 9 & $\begin{array}{c}<1 \\
>15\end{array}$ & 1 & 3 \\
\hline Kecerahan (m) & 3 & $>3$ & 5 & 15 & $1-3$ & 3 & 9 & $<1$ & 1 & 3 \\
\hline $\begin{array}{l}\text { Kecepatan } \\
\text { Arus }(\mathrm{cm} / \mathrm{s})\end{array}$ & 3 & $20-30$ & 5 & 15 & $\begin{array}{l}10-20 \\
30-40\end{array}$ & 3 & 9 & $\begin{array}{l}<10 \\
>40\end{array}$ & 1 & 3 \\
\hline $\begin{array}{l}\text { Suspended } \\
\text { Matter (mg/l) }\end{array}$ & 2 & $<25$ & 5 & 10 & $25-50$ & 3 & 6 & $>50$ & 1 & 2 \\
\hline Salinitas (ppt) & 2 & $32-34$ & 5 & 10 & $30-32$ & 3 & 6 & $\begin{array}{l}<30 \\
>34\end{array}$ & 1 & 2 \\
\hline Suhu $\left({ }^{\circ} \mathrm{C}\right)$ & 2 & $24-30$ & 5 & 10 & $20-24$ & 3 & 6 & $\begin{array}{l}<20 \\
>30\end{array}$ & 1 & 2 \\
\hline $\begin{array}{l}\text { Klorofil -a } \\
(\mathrm{mg} / \mathrm{l})\end{array}$ & 1 & $>10$ & 5 & 5 & $4-10$ & 3 & 3 & $<4$ & 1 & 1 \\
\hline $\begin{array}{l}\text { Substrat } \\
\text { Dasar }\end{array}$ & 1 & Coral & 5 & 5 & Sand & 3 & 3 & mud & 1 & 1 \\
\hline DO (mg/l) & 1 & $>6$ & 5 & 5 & $4-6$ & 3 & 3 & $<4$ & 1 & 1 \\
\hline $\mathrm{pH}$ & 1 & $6.5-8.5$ & 5 & 5 & $\begin{array}{l}4-6.4 \\
8.5-9\end{array}$ & 3 & 3 & $\begin{array}{c}<4 \\
>9.5\end{array}$ & 1 & 1 \\
\hline & & & Total & 125 & & & 75 & & & 25 \\
\hline
\end{tabular}

Sumber: Dimodifikasi dari Hartoko dan Kangkan (2009)

Jika kisaran score total untuk parameter-parameter diatas adalah:
$91.67-125.00$
: Sangat Sesuai
$58.33-91.67$
: Sesuai
$25.00-58.33$
: Tidak Sesuai

Kedalaman perairan di daerah penelitian menunjukan nilai hingga 290,37 m dengan ratarata nilai kedalaman adalah $64,57 \mathrm{~m}$. Pada jarak $100 \mathrm{~m}$ dari bibir pantai, rata-rata kedalaman perairan mencapai $6,36 \mathrm{~m}$ dengan titik terdalam terdeteksi sekitar 79,55 m. Hingga jarak $500 \mathrm{~m}$ dari bibir pantai, rata-rata kedalaman adalah $13,55 \mathrm{~m}$ dengan titik terdalam terdeksi mencapai $173 \mathrm{~m}$. Kedalaman perairan yang terpengaruh oleh pasang surut merupakan salah satu faktor yang harus diperhatikan dalam budidaya rumput laut, posisi ideal adalah ketika surut terendah rumput laut tidak terkena sinar matahari secara langsung dan masih memperoleh penetrasi matahari pada waktu pasang 
(Sediadi et al., 2000 dalam Sulma et al., 2008) sedangkan pada perairan yang lebih dalam, kedalaman perairan dapat disiasati dengan pemilihan teknik budidaya yang tepat, misalnya dengan metode budidaya apung yang menyebabkan rumput laut relatif mengikuti naik turunnya pasang surut (Ambas, 2006).

Sebaran kecerahan di daerah penelitian menunjukkan bahwa rata-rata kecerahan sebesar $12,15 \mathrm{~m}$, dengan kecerahan minimal terdeteksi 5,00 m hingga maksimal 19,00 m. Standar deviasi sebaran kecerahan di daerah penelitian menunjukkan nilai $2,33 \mathrm{~m}$, hal ini menunjukkan bahwa sebaran kecerahan di daerah penelitian cukup beragam dengan kondisi perairan yang relatif jernih. Budidaya rumput laut membutuhkan perairan yang mempunyai kecerahan tinggi agar sinar matahari dapat menembus perairan yang dibutuhkan dalam mekanisme fotosintesa. Penetrasi cahaya menjadi rendah apabila tingginya kandungan partikel tersuspensi di perairan dekat pantai, akibat aktivitas pasang surut.

Rata-rata kecepatan arus pada lokasi penelitian adalah sebesar 10,9 cm/s, dengan kecepatan arus minimal terdeteksi $9,9 \mathrm{~cm} / \mathrm{s}$ hingga maksimal 11,5 $\mathrm{cm} / \mathrm{s}$. Arus merupakan salah satu parameter penting dalam sirkulasi air, pembawa bahan terlarut dan padatan tersuspensi serta dapat berdampak pada keberadaan organisme penempel. Kecepatan arus perairan untuk budidaya keramba jaring apung di laut tidak boleh lebih dari 100 $\mathrm{cm} /$ detik dan kecepatan arus bawah $25 \mathrm{~cm} / \mathrm{dt}$. Sedangkan untuk rumput laut $20-30 \mathrm{~cm} / \mathrm{dt}$ dan tiram mutiara berkisar $15-25 \mathrm{~cm} / \mathrm{dt}$.

Adanya arus di laut disebabkan oleh perbedaan densitas masa air laut, tiupan angin terus menerus diatas permukaan laut dan pasang-surut terutama di daerah pantai. Pasang surut juga dapat menggantikan air secara total dan terus menerus sehingga perairan terhindar dari pencemaran.

Arus mempunyai pengaruh positif dan negatif bagi kehidupan biota perairan. Arus dapat menyebabkan ausnya jaringan jazad hidup akibat pengikisan atau teraduknya substrat dasar berlumpur yang berakibat pada kekeruhan sehingga terhambatnya fotosintesa. Pada saat yang lain, manfaat dari arus adalah menyuplai makanan, kelarutan oksigen, penyebaran plankton dan penghilangan $\mathrm{CO}_{2}$ maupun sisa-sisa produk biota laut.
Muatan Padatan Terlarut (MPT) atau Total Dissolved Solids (TDS) adalah benda padat yang terlarut, yaitu semua mineral, garam, logam serta kation-anion yang terlarut dalam air. Benda-benda padat dalam air tersebut berasal dari banyak sumber organik seperti daun, lumpur, plankton, serta limbah industri dan kotoran. Sumber lainnya bisa berasal dan limbah rumah tangga, pestisida, dan banyak lainnya. Sedangkan, sumber anorganik berasal dari batuan dan udara yang mengandung kasium bikarbonat, nitrogen, besi fosfor, sulfur, dan mineral lain.

Hasil pengamatan MPT pada tiap stasiun pengamatan menunjukkan bahwa perairan di sekitar Teluk Saleh relatif jernih dengan kandungan materi tersuspensi yang tidak begitu tinggi. Berdasarkan Keputusan Menteri Negara Lingkungan Hidup, standar baku mutu padatan tersuspensi untuk biota laut berada kisaran 20-80 $\mathrm{mg} / \mathrm{l}$, sedangkan pengukuran lapangan menunjukkan bahwa rata-rata nilai MPT sebesar $52,2 \mathrm{mg} / \mathrm{l}$, dengan nilai MPT minimal terdeteksi $51,7 \mathrm{mg} / \mathrm{l}$ hingga maksimal $52,5 \mathrm{mg} / \mathrm{l}$. Hal ini menunjukkan bahwa sebaran MPT di daerah penelitian cukup seragam dan berada pada rentang baku mutu untuk biota laut tersebut. Materi yang tersuspensi mempunyai dampak buruk terhadap kualitas air karena mengurangi penetrasi matahari ke dalam badan air, kekeruhan air meningkat yang menyebabkan gangguan pertumbuhan bagi organisme produser terutama sebagai penghasil oksigen (Masser, 1997).

Pada survey ini pengukuran parameter salinitas dilakukan dengan menggunakan alat ukur portabel Eutech Salt 6+. Hasil pengukuran lapangan disekitar daerah penelitian menunjukkan bahwa secara umum nilai salinitas permukaan berada pada kisaran $31 \%$. Curah hujan akan dapat menurunkan kadar salinitas karena air hujan mempunyai salinitas yang rendah sedangkan penguapan akan menyebabkan tingginya salinitas pada suatu perairan. Sebaran salinitas di daerah penelitian menunjukkan bahwa rata-rata nilai salinitas sebesar 31,6 ppt, dengan nilai salinitas minimal terdeteksi 31,3 ppt hingga maksimal 31,8 ppt. Hasil yang hampir sama diperoleh oleh Radiarta et al. (2004) dengan rentang salinitas 2232 ppt, namun masih berada pada kisaran ideal untuk budidaya rumput laut (Ambas, 2006). Perairan yang berdekatan dengan muara tidak dianjurkan untuk lokasi budidaya secara umum 
karena kadar salinitas sangat berfluktuasi yang diakibatkan oleh masuknya air tawar dari sungai. Fluktuasi tersebut dapat mempengaruhi pertumbuhan biota yang dibudidayakan.

Suhu rata-rata di daerah penelitian di Teluk Saleh yang diperoleh dari citra satelit Aqua MODIS, level 2 harian dengan resolusi piksel $1 \mathrm{~km}$ adalah 29,07 ${ }^{\circ} \mathrm{C}$, dengan suhu terendah terdeteksi pada nilai $27,28^{\circ} \mathrm{C}$, dan suhu tertinggi terdeteksi di nilai $33,23{ }^{\circ} \mathrm{C}$. Sedangkan suhu rata-rata hasil pengukuran langsung pada rentang waktu antara jam 09.00 WITA sampai dengan 16.00 WITA adalah $28,6^{\circ} \mathrm{C}$. Kisaran tersebut masih merupakan rentang ideal untuk pertumbuhan rumput laut berdasarkan SNI 7579.1:2010 yaitu dengan rentang 26- $32^{\circ}$ C. Substrat dasar yang bisa dideteksi melalui sistem penginderaan jauh adalah karang, karang mati, lamun dan pasir. Karang hidup tersebar merata di sepanjang pesisir Teluk Saleh dengan total luasannya mencapai 10.029,6 ha. Karang ini tersebar di perairan dengan kedalaman antara 0-27,22 m,dengan sebaran terbanyak di kedalaman 0-7,9 m. Karang mati tersebar di beberapa titik di pesisir Teluk Saleh dengan total luasannya mencapai 863,01 ha. Karang mati ini terdeteksi tersebar pada kedalaman 0-44.9 m dengan sebaran tertinggi pada kedalaman 0-13.1 $\mathrm{m}$. Lamun tersebar di beberapa titik di pesisir Teluk saleh dengan total luasannya mencapai 19,92 ha. Sebaran lamun tertinggi terdapat di daerah dengan kedalaman 0 - 8,2 m. Dasar perairan yang sebagian besar terdiri dari karang diduga menjadi salah satu penyebab jernihnya perairan di sekitar Teluk Saleh. Dasar perairan dengan pecahan karang merupakan dasar perairan yang ideal untuk rumput laut, jika dibandingkan dengan dasar perairan yang berlumpur.

Konsentrasi klorofil-a permukaan di daerah penelitian di Teluk Saleh dalam penelitian ini dipantau dari bulan Juli 2011 sampai Juni 2012. Rata-rata konsentrasi klorofil-a permukaan yang diperoleh dari citra satelit Aqua MODIS, level 2 harian dengan resolusi piksel $1 \mathrm{~km}$ adalah sebesar $0,87 \mathrm{mg} / \mathrm{m}^{3}$ dengan konsentrasi klorofil-a permukaan terendah terdeteksi pada nilai 0,19 $\mathrm{mg} / \mathrm{m}^{3}$, sedangkan konsentrasi klorofil-a permukaan tertinggi terdeteksi di nilai 76,03 $\mathrm{mg} / \mathrm{m}^{3}$. Standar deviasi konsentrasi klorofil-a permukaan laut sebesar $1,70 \mathrm{mg} / \mathrm{m}^{3}$ menunjukkan bahwa sebaran konsentrasi klorofil-a permukaan laut di lokasi penelitian cukup beragam. Sebaran konsentrasi klorofil-a permukaan paling banyak berada pada kisaran di bawah $1 \mathrm{mg} / \mathrm{m}^{3}$. Klorofil-a permukaan bukanlah faktor utama dalam penentuan lokasi untuk budidaya rumput laut, namun dapat digunakan sebagai acuan apakah pada daerah tersebut terjadi ledakan pertumbuhan fitoplankton akibat tingginya nutrien yang dapat mengganggu kelangsungan budidaya rumput laut.

Sebaran DO di daerah penelitian menunjukkan bahwa rata-rata nilai DO sebesar $3,7 \mathrm{mg} / \mathrm{l}$, dengan nilai salinitas minimal terdeteksi $3,6 \mathrm{mg} / \mathrm{l}$ hinggamaksimal $3,85 \mathrm{mg} / \mathrm{l}$, nilai tersebut sedikit lebih rendah dari standar baku mutu untuk biota laut yang dikeluarkan oleh Kementerian Lingkungan Hidup. Rendahnya kandungan oksigen ini didugakarena masuknya bahan-bahan organik ke perairan, sehingga memerlukan banyak oksigen untuk menguraikannya. Ada beberapa hal yang dapat menyebabkan berkurangnya oksigendalam air, antara lain: respirasi biota, dekomposisi bahan organik dan pelepasan oksigen ke udara (Ulqodry et al., 2010).

Derajat keasaman $(\mathrm{pH})$ merupakan salah satu parameter kimia yang penting dalam memantau kestabilan perairan dan setiap biota laut mempunyai nilai toleransi yang berbeda-beda terhadap variasi $\mathrm{pH}$ (Simanjuntak, 2012). Sebaran $\mathrm{pH}$ di daerah penelitian menunjukkan bahwa ratarata nilai $\mathrm{pH}$ sebesar 8,9 , dengan nilai $\mathrm{pH}$ minimal terdeteksi 8,95 hingga maksimal 9,08. Nilai tersebut sedikit lebih tinggi dari nilai ambang batas yang ditetapkan Kementerian Lingkungan Hidup, namun masih berada pada kisaran yang sesuai untuk kehidupan rumput laut (Hartoko dan Kangkan, 2009).

Sebaran spasial parameter kualitas perairan di Teluk Saleh dapat dilihat pada Gambar 3.

\subsection{Zona Potensial untuk Budidaya Rumput Laut}

Penentuan kawasan untuk pengembangan budidaya rumput laut dengan mempertimbangkan faktorfaktor lingkungan, terutama yang dapat dipantau dengan menggunakan satelit penginderaan jauh dan dipadukan dengan data lapangan, diharapkan mampu memberikan informasi awal dalam penataan kawasan di wilayah perairan Teluk Saleh. Proses penentuan wilayah perairan yang sesuai bagi kegiatan budidaya rumput laut ini disusun dengan menggunakan beberapa parameter kualitas 
perairan yaitu fosfat, nitrat, kedalaman perairan, kecerahan, kecepatan arus, material padatan tersuspensi, salinitas, suhu perairan, substrat dasar, konsentrasi klorofil-a, DO dan $\mathrm{pH}$. Keduabelas parameter tersebut kemudian dianalisis pada perangkat lunak Sistem Informasi Geografis dengan menggunakan analisis tumpang susun (overlay).

Sebelumnya, masing-masing parameter tersebut telah diberi bobot dan score sehingga setelah dilakukan overlay analisis akan terlihat secara spasial kisaran nilai kesesuaian untuk budidaya rumput laut (Gambar 4).
Nilai kesesuaian hasil analisis untuk budidaya rumput laut berkisar antara 49 sampai 77.

Berdasarkan kisaran scoring yang telah ditentukan sebelumnya, maka pada lokasi penelitianhanya dapat dibagi menjadi dua kategori saja, yaitu ketegori sesuai dan tidak sesuai untuk budidaya rumput laut. Gambar 5 menunjukkan daerah yang termasuk kedalam kategori sesuai untuk pengembangan budidaya rumput laut dengan luasan sekitar 25.532,57 Ha atau sekitar 24\% dari total luasan studi.

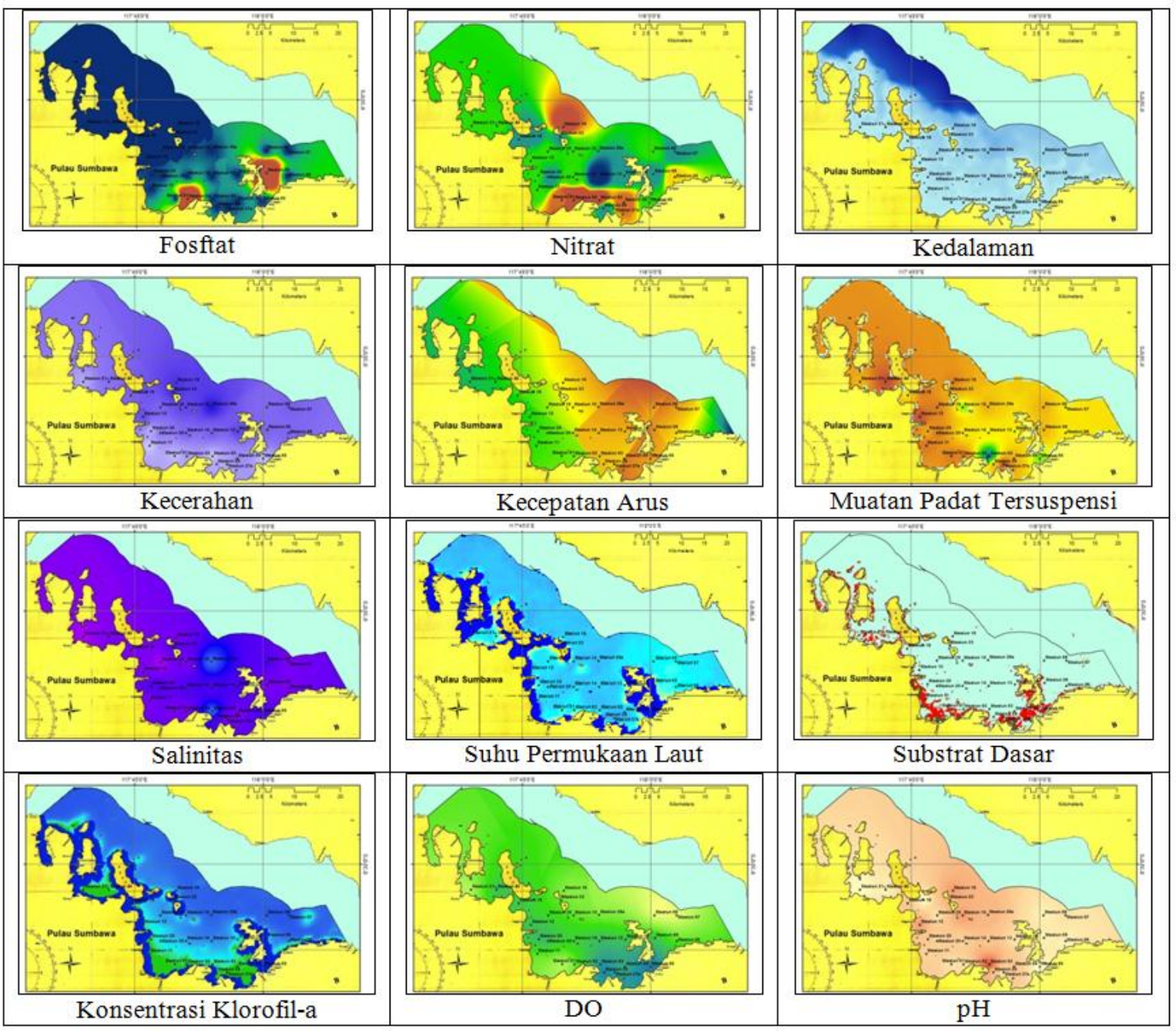

Gambar 3. Sebaran spasial kualitas perairan Teluk Saleh, Sumbawa, NTB

Figure 3. Spatial distribution of water quality in Saleh Bay, NTB

Sumber: Hasil pengolahan data 


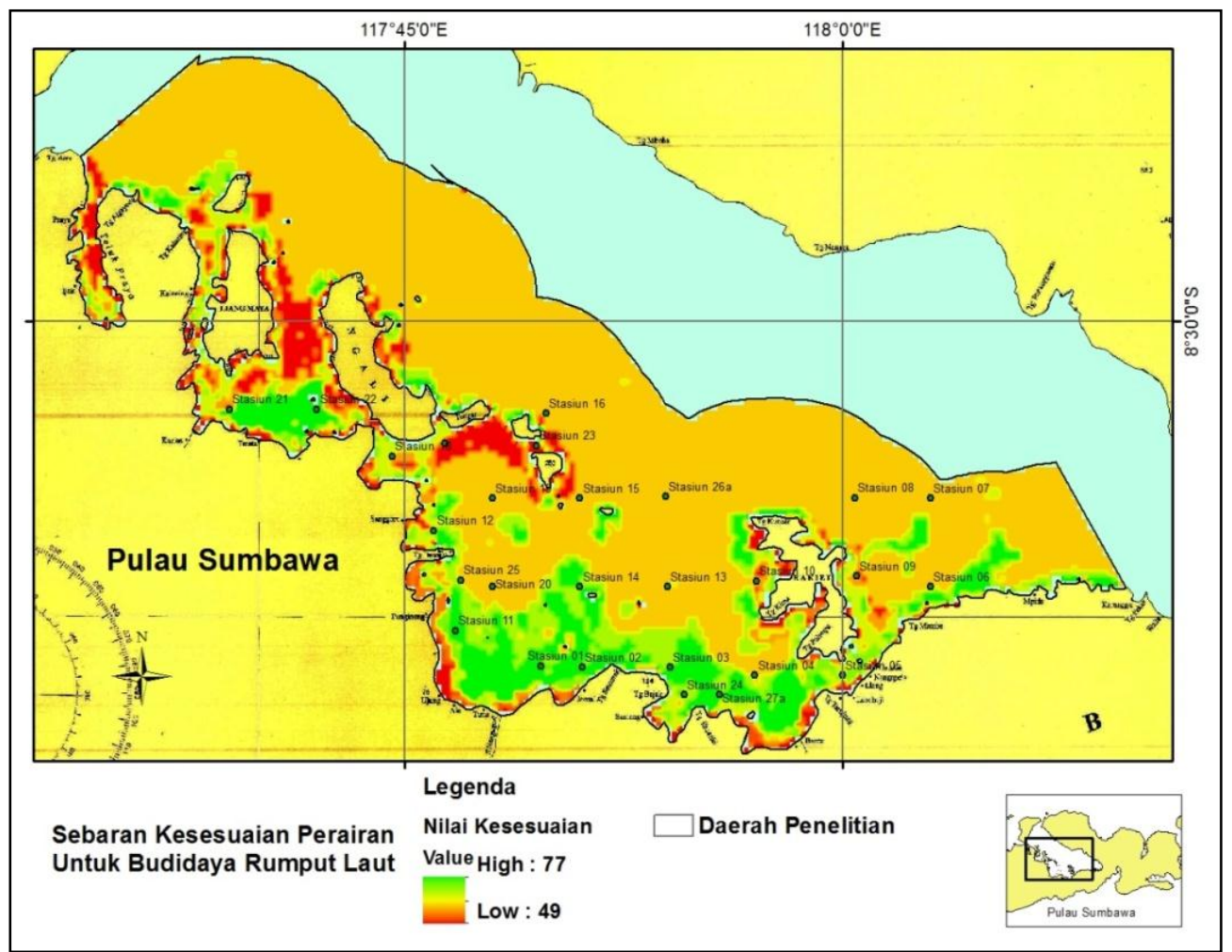

Gambar 4. Hasil analisis metode overlay pada daerah penelitian Figure 5. Result of overlay analysis Sumber: Hasil analisis

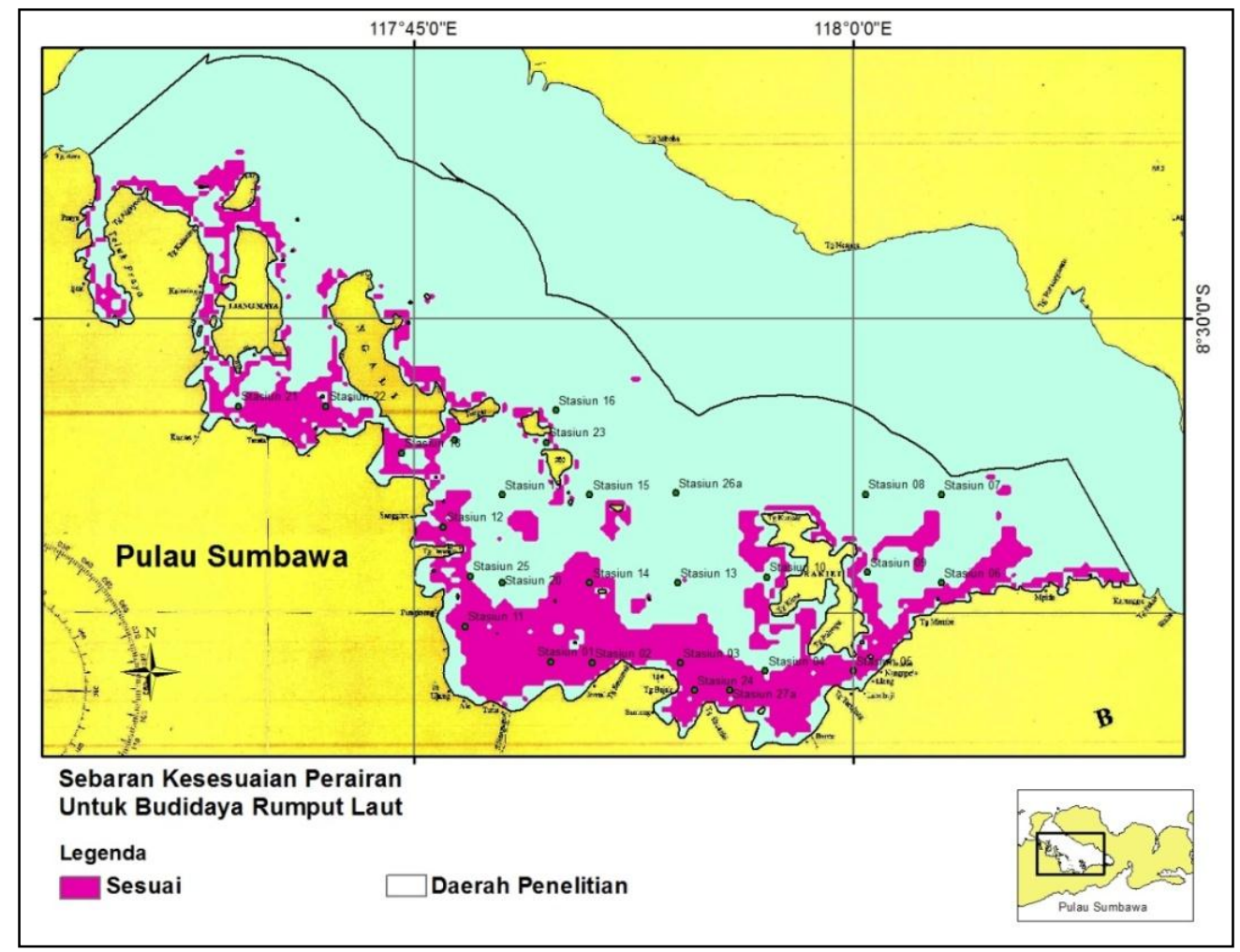

Gambar 5. Zona potensial untuk budidaya rumput laut

Figure 5. Potential zone for seaweed culture

Sumber: Hasil analisis 


\section{KESIMPULAN DAN SARAN}

Secara umum kualitas perairan Teluk Saleh masih berada dalam kondisi yang sesuai untuk pengembangan budidaya rumput laut. Analisis dengan menggunakan SIG menunjukkan bahwa lokasi perairan yang potensial dan termasuk kedalam kategori yang sesuai untuk pengembangan rumput laut di wilayah perairan Teluk Saleh adalah sekitar 25.532,57 $\mathrm{Ha}$ atau sekitar 24\% dari total luasan studi. Dengan adanya informasi awal ini, maka kegiatan perencanaan pengembangan wilayah perairan untuk pembangunan sektor kelautan dan perikanan dapat dilakukan dengan lebih terarah serta pengembangan pola budidaya yang ramah lingkungan wajib diterapkan sehingga kegiatan budidaya dapat dilakukan secara berkelanjutan.

\section{DAFTAR PUSTAKA}

Aguilar-Manjarrez, J., \& Ross, L. G. (1995). Geographical Information System (GIS) environmental model for aquaculture development in Sinaloa State, Mexico. Chapman and Hall. P 103-115.

Ambas, I. (2006). Pelatihan Budidaya Laut (Coremap Fase II Kab. Selayar). Yayasan Mattirotasi.

Buitrago J., Rada, M., Hernandez, H., \& Buitrago, E. (2005). A single-use site selection technique, using GIS, for aquaculture planning: Choosing location for mangrove oyster raft culture in Margarita Island, Venezuela. Environmental Management, 35(5), 544-556.

Carswell, B., Cheesman, S., \& Anderson, J. (2006). The use of spatial analysis for environmental assessment of sellfish aquaculture in Bayness Sound, Vancouver Island, British Columbia, Canada. Aquaculture, 253, 408-414.

Fakultas Perikanan dan Ilmu Kelautan Universitas Riau. (2008). Identifikasi dan Pemetaan Pengembangan Budidaya Rumput Laut di Wilayah Coremap II Kabupaten Bintan. Laporan Akhir. Pekanbaru.

Hartoko, A., \& Kangkan, A. L. (2009). Spatial modelling for mariculture site selection based on ecosystem parameter at Kupang Bay, East Nusa Tenggara Indonesia. International Journal of Remote Sensing and Earth Science, 6, 57-64.

Masser, M. P. (1997). Cage culture: Site selection and water quality. Auburn University and publish by Southern Regional Aquaculture Centre. Retrieved November 11, 2010, from http://www.thefishsite.com/articles/323/cage-

culture-site-selection-and-water-quality.

Perez, O. M., Ross, L. G., Telfer, T. C., \& del Campo Barquin, L. M. (2003). Water quality requirement for marine fish cage site selection in Tenerife (Canary Island): Predictive modelling and analysis using GIS. Aquaculture, 224, 5168.

Radiarta, I N., Saputra, A., \& Priono, B. (2004). Pemetaan kelayakan lahan untuk pengembangan usaha budidaya laut di Teluk Saleh, Nusa Tenggara Barat. Jurnal Penelitian Perikanan Indonesia, 10(5), 19-32.

Radiarta, I N., Saitoh, S. I., \& Miyazono, A. (2008). GIS-based multi-criteria evaluation models for identifying suitable site for Japanesse scallop (Mizuhupecten yessoensis) aquaculture in Funka Bay, Southwestern Hokkaido, Japan. Aquaculture, 284, 127-135.

Simanjuntak, M. (2012). Kualitas air laut ditinjau dari aspek zat hara, oksigen terlarut dan $\mathrm{pH}$ di perairan Banggai, Sulawesi Tengah. Jurnal Ilmu dan Teknologi Kelautan Tropis, 4(2), 290-303.

Sulma, S., Mannopo, A. K. S., \& Indarto, D. (2008). Pemanfaatan data penginderaan jauh untuk kajian potensi budidaya perikanan laut. Laporan. Pusat Pengembangan Pemanfaatan dan Teknologi Penginderaan Jauh. LAPAN.

Suniada, K. I. (2011). Utilization of remote sensing satellite data to determine a suitable area for mariculture around Morotai Island - North Maluku. Proceeding $2^{\text {nd }}$ CReSOS International Symposium on South East Environment Problems and Satellite Remote Sensing, 89-96.

Suniada, K. I., Realino, B., dan Indriyawan, M. W. (2012). Pemanfaatan data satelit penginderaan jauh untuk penentuan lokasi budidaya rumput laut di Desa Kaliuda, Kec. Pahungalodu, Kab. Sumba Timur - NTT. Ecotrophic, 7(1), 16-27.

Ulqodry, T. Z., Yulisman, Syahdan, M., \& Santoso. (2010). Karakteristik dan sebaran nitrat, fosfat dan oksigen terlarut di perairan Karimunjawa Jawa Tengah. Jurnal Penelitian Sains, 13, 35-41.

Utojo, Mansyur, A., Tangko, A. M., Hasnawi, \& Mulia, T. (2007). Pemilihan lokasi budidaya ikan, rumput laut dan kerang mutiara yang ramah lingkungan di Teluk Tomini, Sulawesi Tengah. Pengembangan Teknologi Budidaya Perikanan. BBRPBL. 200-210. 
